\title{
"Você mandou eu cantar, na mente que eu não sabia": estruturação formal e camuflagem em um gênero musical camponês do médio Jequitinhonha ${ }^{1}$
}

Leonardo Pires Rosse (pesquisador independente, Belo Horizonte, MG)

piresrosse@yahoo.com.br

Resumo: 0 paulista é um importante gênero músico-coreográfico camponês no médio Jequitinhonha (Minas Gerais). A partir da análise formal de alguns de seus parâmetros técnicos, este artigo busca explorar mecanismos através dos quais uma forma musical e literária pode propor um enunciado coerente e ao mesmo tempo dificultar ou restringir sua apreensão. Esta "codificação" acontece aqui através de processos de estruturação formal de um lado, aliados a uma particular economia de qualquer discurso analítico ou não-musical sobre a prática musical, de outro. Por fim, uma curta comparação de caso pretende sugerir tal problema como um paradigma possivelmente pertinente a outros contextos camponeses no Brasil.

Palavras-chave: folião; paulista; música camponesa; estruturação musical; conteúdo semântico.

"Você mandou eu cantar, na mente que eu não sabia": formal structuring and camouflage in a peasant musical genre from the mid Jequitinhonha river (south-east of Brazil)

Abstract: The paulista is an important musico-choreographic peasant genre from the mid Jequitinhonha river (Minas Gerais, south-east of Brazil). Starting with a formal analysis of some of its technical parameters, this article seeks to explore mechanisms through which a musical and literary form can propose a coherent statement and at the same time difficult or restrict its apprehension. This "codification" is done here through processes of formal structuring on one hand, combined to a particular economy of any analytical or not-musical discourse about the musical practice, on the other hand. At last, a short comparison of cases claims to suggest such problem as a paradigm possibly relevant to other peasant contexts in Brazil.

Keywords: folião; paulista; peasant music of Brazil; musical structuring; semantic content.

\section{1 - Introdução}

0 termo "foliões", em Turmalina (Minas Gerais), designa os responsáveis pela música e dança das festas em comunidades rurais do município. Diferentes gêneros músico-coreográficos fazem parte do repertório dos foliões, gêneros ligados a momentos específicos dentro das festas, ou a festivais específicos de seu calendário. Estes festivais estão intimamente ligados à religiosidade, onde a música exerce um papel importante na comunicação entre homens e santos católicos.

De um ponto de vista simplesmente musical, os foliões são sobretudo cantores: o acompanhamento instrumental se faz geralmente presente (principalmente com viola caipira, violão e caixa), mas o investimento principal reside no canto e nas letras cantadas. Alguns dos gêneros músicocoreográficos deste contexto são abertos à participação de todos os presentes; a performance de outros é restrita aos foliões, assistidos então por um público. Em ambos os casos, a música, suas letras e a dança traçam uma série de relações pessoais entre os foliões, entre estes e seus anfitriões, entre os anfitriões e outros convidados, entre humanos e santos, enfim, em diversas direções entre os diferentes agentes da situação. Os foliões devem então dominar um sistema de códigos técnicos (musicais, literários, coreográficos) e de relações destes códigos a uma forma específica de sociabilidade experimentada durante a 
prática musical. A qualidade musical é aqui indissociável da qualidade das alianças criadas ou atualizadas entre os diferentes sujeitos através do próprio exercício musical. Desta forma, erros e má qualidade de uma performance podem acarretar prejuízo social, e inversamente, o sucesso musical constitui uma importante chave na construção de uma sócio-cosmologia².

A prática dos foliões está associada a uma série extensa de regras, restrições, princípios de estruturação formal, prescrições de condução melódica das diferentes vozes, enfim, a uma gramática musical suficientemente complexa e sutil para ser percebida com graus diferentes de apreensão entre foliões e espectadores mais ou menos cultos. Embora esta fineza perceptiva seja um objetivo coletivamente partilhado, notamos a ausência quase deliberada de todo discurso teórico ou não-musical sobre a prática musical. 0 aprendizado desta gramática passa essencialmente pela experiência da performance e de sua escuta. 0 vocabulário musicológico e coreográfico deste contexto é significativamente reduzido: existem poucos termos para falar de música e vários deles são imprecisos ou polissêmicos. Estaríamos então diante de um aparente paradoxo entre o que seria uma cultura do virtuosismo e um discurso teórico (analítico, abstrato, descritivo) quase ausente. Este contraste parece apontar uma valorização da própria complexidade gramatical deste repertório.

Como os camponeses de uma forma geral no Brasil, os foliões de Turmalina e seu "público" são frequentemente associados por sua representação oficial nacional a uma "inocência perdida" no mundo moderno industrializado, a uma "ingenuidade intelectual" e a uma "ignorância generalizada", devidos a um suposto "isolamento geográfico" (cf. BRANDÃO, 1983; CANDIDO, 2003 [1964]; MOREIRA, 2005; RODRIGUES, 2008). No extremo oposto deste estereótipo, estes camponeses se mostrariam grandes intelectuais no interior de um sistema de códigos acessiveis apenas a um número restrito de "iniciados".

A partir da análise formal de alguns parâmetros técnicos de um importante gênero músico-coreográfico dos foliões - o "paulista" - este artigo busca problematizar brevemente mecanismos através dos quais uma forma musical e literária pode propor um enunciado coerente e ao mesmo tempo dificultar sua apreensão, ou restringila. Esta "codificação" seria feita, como veremos, através de procedimentos de estruturação formal de um lado, aliados a uma particular economia de qualquer discurso analítico ou não-musical sobre a prática musical, de outro. Por fim, uma curta comparação de caso pretende sugerir tal problema como um paradigma possivelmente pertinente a outros contextos camponeses no Brasil.

\section{2 - Algumas considerações preliminares}

Em Turmalina, ou nos bairros rurais vizinhos, é frequente que as festas comunitárias ou privadas recebam os foliões como convidados de honra. Como mencionamos acima, estes são especialistas de música e dança, grandes responsáveis então pela animação e êxito da ocasião. Em uma festa com foliões, diversos gêneros músicocoreográficos serão "brincados" e estas "brincadeiras", cuja execução pode ser mais ou menos virtuose, podem integrar um número maior ou menor de participantes, e serem abertas ou não à participação de não-foliões.

Todos os gêneros musicais deste contexto são cantados e reservam um espaço aberto à construção, em tempo real, de suas letras. Uma peça qualquer possui geralmente versos invariáveis e exclusivos, aos quais são acrescentados, em cada execução, diferentes versos escolhidos no próprio instante de sua realização. Este procedimento é chamado "jogar verso". De forma geral, estes versos "jogados" não são criados durante a performance musical, mas selecionados dentro de um vasto repertório pré-existente e comum a diferentes gêneros musicais.

No contexto local, o termo "verso" é às vezes ambíguo na distinção entre verso e estrofe, tal qual o entendemos na teoria literária acadêmica. 0 último termo ("estrofe") não existe no vocabulário musicológico dos foliões de Turmalina. Proponho aqui mantermos esta terminologia, indicando entretanto entre parênteses 0 sentido específico de "verso" ou "estrofe", quando o texto exigir este tipo de precisão. Desta maneira, utilizaremos as fórmulas "verso (verso)" ou "verso (estrofe)", de acordo com o sentido específico atribuído à palavra.

0 conjunto de versos que caracteriza uma determinada peça - aqueles que Ihe são exclusivos e sempre presentes em seu interior - será chamado aqui de "estrofe característica" de tal peça. Esta expressão é igualmente estrangeira ao vocabulário próprio ao contexto estudado, sendo proposta então por fins de comodidade descritiva.

\section{3 - As Vozes}

\section{1 - Sistema de condução melódica - o canto restrito pela estrutura}

0 paulista é um gênero frequentemente apontado entre os foliões como belo e, além de seu papel de divertimento, sua vocação de objeto de fruição estética já foi observada alhures (ROSSE, 2009a e 2009b). Ele é realizado geralmente em um ponto avançado ou pouco eufórico de uma festa, momentos onde um certo ambiente de concentração é buscado. Sua prática é reservada apenas aos foliões, e mesmo assim, aos foliões experientes. Da mesma forma, sua escuta parece ser buscada sobretudo por um público mais experiente, capaz de compreendê-lo de forma apropriada.

Utiliza-se aqui um sistema de condução melódica das vozes comum também a outros gêneros cantados pelos foliões. Trata-se de um sistema a quatro vozes, chamadas "primeira", "segunda", "contrato" e "requinta". É o folião que canta a primeira quem escolhe a peça que será cantada e os versos que serão jogados durante a mesma. Estas decisões são normalmente comunicadas aos outros cantores exclusivamente através da performance, em tempo real: o folião que "dá" a primeira começa a 
cantar uma peça qualquer e o resto do grupo o segue instantaneamente.

Também em um nível melódico a linha cantada pela primeira é uma referência indispensável para a condução das outras três partes. A composição destas é pensada sempre em relação à melodia reproduzida pela primeira, a qual vamos chamar aqui, justamente por esta razão, de "melodia principal". Esta melodia principal é a única linha eventualmente isolada das outras, cantada à vezes individualmente para indicar uma peça fora de seu contexto de performance.

Além da primeira, não se pensa tampouco em memorizar partes ou melodias específicas, mas sim em desenvolver a habilidade de decodificar uma melodia principal qualquer, e de colocar outra voz em relação a ela. Um folião pode nunca ter ouvido uma peça e ser entretanto capaz de acompanhá-la sem problemas. Este é inclusive um exemplo bem concreto de uma situação bastante frequente. Mais do que aprender peças particulares, o cantor deve aprender a dominar um sistema de condução melódica.

Como sabemos é sempre a pessoa que canta a primeira quem começa o canto. Ela cantará então uma melodia determinada, obrigatoriamente memorizada a priori. A segunda começa a cantar logo em seguida, algumas notas após. Ela segue basicamente uma linha melódica paralela à primeira, num intervalo harmônico de uma terça diatônica abaixo desta.

0 contrato entra um pouco depois da segunda. Mesmo a partir de sua entrada, ele não canta exatamente 0 mesmo número de notas que a primeira e a segunda, nem em total homofonia ou paralelismo. Sua linha é formada de durações mais longas e baseada em duas alturas principais: o primeiro e o quinto graus da escala diatônica, sempre numa mesma oitava, entre as notas da melodia principal e da requinta, a voz mais aguda dentre as quatro, que veremos mais adiante.
Como as frases neste contexto musical são geralmente apoiadas sobre as funções harmônicas de tônica, dominante, ou subdominante, as notas de base da linha do contrato constituem sempre a quinta ou a fundamental destes acordes. Geralmente se a função harmônica é de tônica, a primeira canta a terça ou a quinta do acorde. 0 contrato cantará nestes casos sua quinta ou sua fundamental (ou seja: ou o quinto, ou o primeiro grau da escala). Quando a função é de dominante, a primeira canta a terça, a quinta, ou às vezes a sétima do acorde, sobre as quais o contrato cantará a fundamental (quinto grau da escala). Se a função for de subdominante, a primeira cantará a terça do acorde, o contrato cantará sua quinta (primeiro grau da escala).

Entre estas notas de base do contrato, é comum que o "contrateiro" (cantor do contrato) respire, marcando uma ligeira pausa, ou que ele cante ornamentos e notas de passagem. Esta linha constrói um tipo de heterofonia rítmica em relação à melodia principal, uma pequena variação que suprime algumas notas, alonga durações, distorce ligeiramente figuras rítmicas.

A requinta entra ainda depois do contrato, e quando este para em respirações, ela para também, só voltando depois que ele volta. Em geral, o "requinteiro" (cantor da requinta) não deve começar a cantar antes que todas as outras três vozes já estejam soando. A requinta mantém basicamente 0 intervalo harmônico de uma oitava acima da segunda, ou seja, uma sexta diatônica acima da primeira, guardando algumas notas mais longas em relação a estas vozes, e alguns pequenos portamentos descendentes em fins de frases.

Tomemos como exemplo a melodia seguinte, apresentada no Ex.1, cantada pela primeira sobre os quatro primeiros versos (versos) de uma peça de paulista (sobre a qual voltaremos mais tarde):

Esta melodia poderia ser resolvida por quatro foliões da seguinte maneira, como nos mostra o Ex.2:

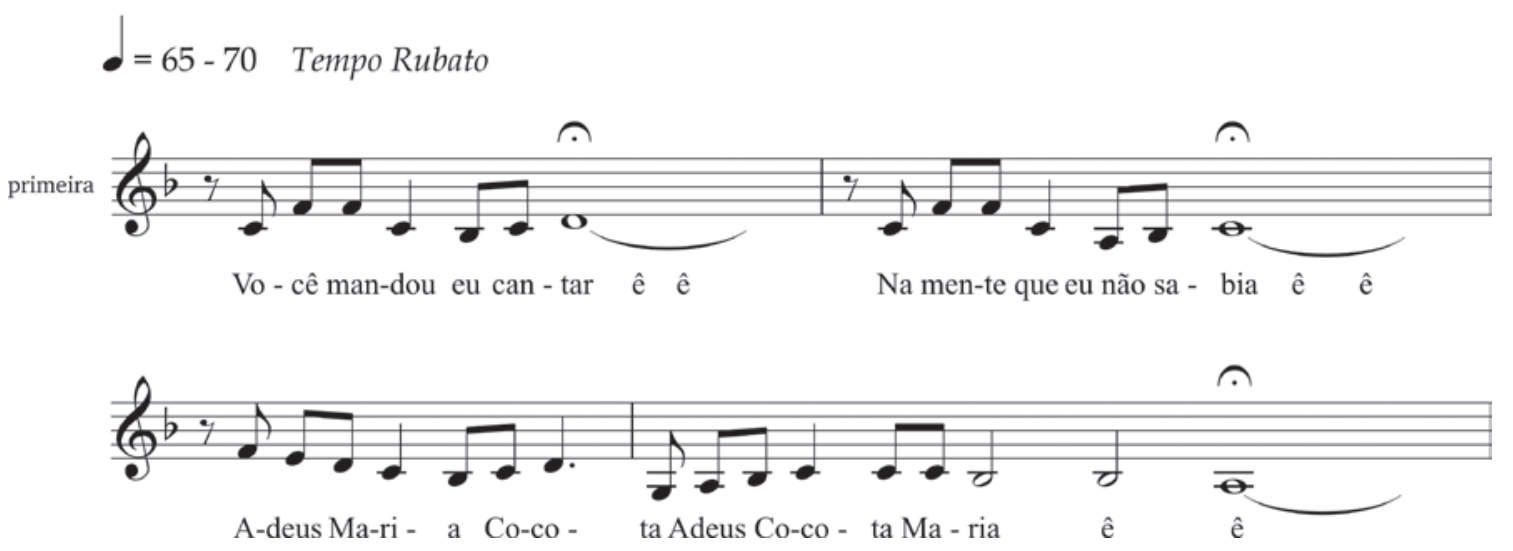

Ex.1 - Trecho de melodia cantada pela primeira em uma peça de paulista. 


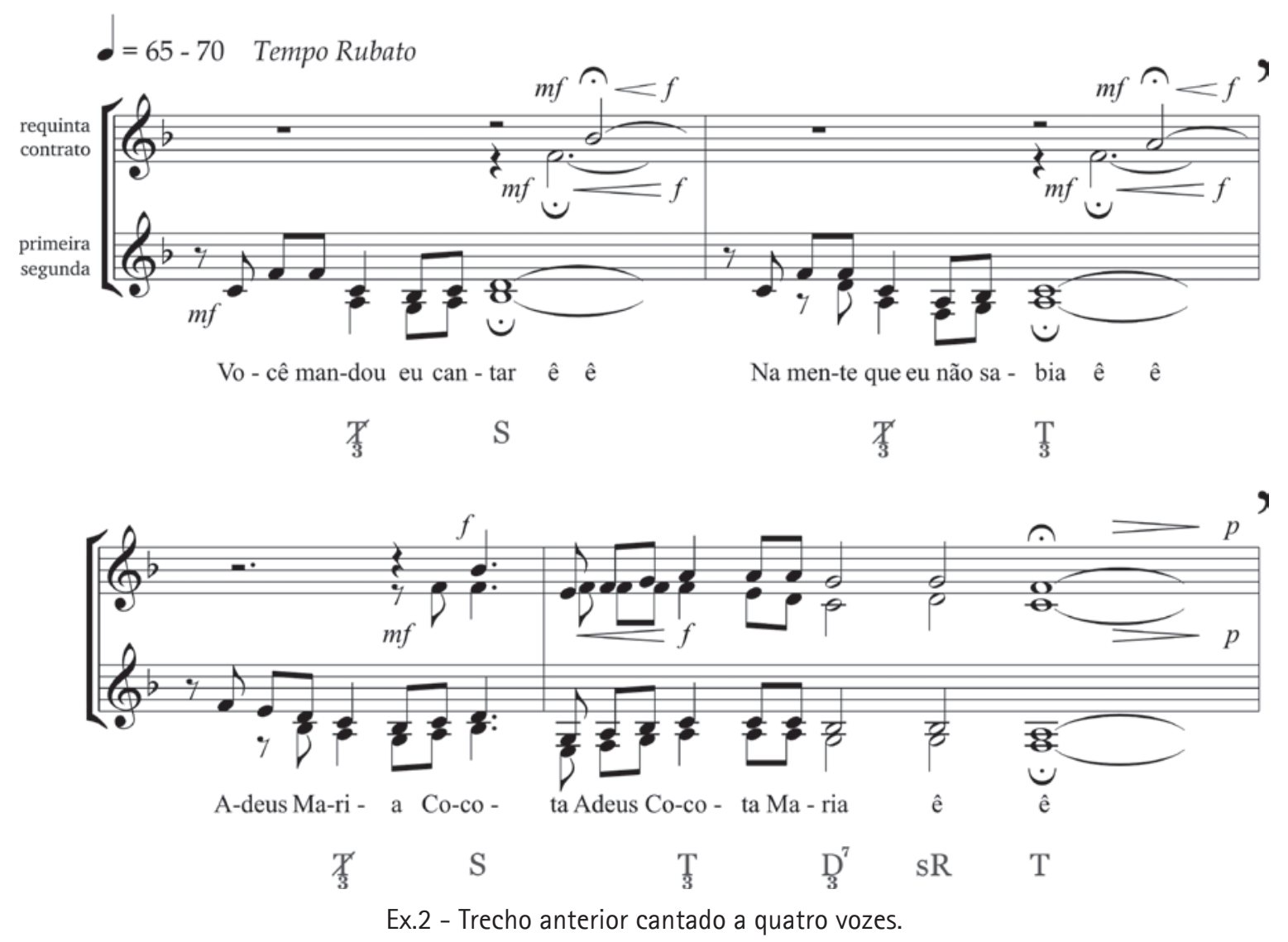

Se por um lado podemos entender a linha melódica cantada pela primeira como um tipo de resumo de todas as outras partes, um texto onde encerram-se todos os elementos necessários para que um folião experiente possa conceber as outras três linhas, por outro lado, devemos ter em mente que, sem a primeira, ou sem a habilidade necessária para decodificá-la, não há canto viável. Poderíamos pensar aqui em um sistema de restrição do canto, reservado neste caso aos cantores experientes, condicionado à presença sine qua non da voz primeira.

\section{2 - Registros vocais, intensidade sonora e dicção - a letra dissolvida na melodia}

Dois outros parâmetros são muito significativos na distinção de cada parte vocal em relação à primeira: a maneira em que seus cantores pronunciam as palavras das letras; os registros vocais utilizados e a intensidade de cada parte.

A primeira e a segunda utilizam o mesmo registro laríngeo: a voz de peito, ou "Mecanismo I", para adotarmos a terminologia proposta pelo Laboratoire d'Acoustique Musicale do CNRS - Centre National de la Recherche Scientifique ${ }^{3}$. As duas partes articulam também igualmente bem os fonemas das palavras, cantando um texto claro, totalmente inteligivel. A segunda normalmente canta com um pouco menos de intensidade que a primeira, mas as duas vozes mantêm um volume relativamente regular, sem variações significativas de amplitude.

0 contrateiro canta ainda dentro do primeiro registro, mas suas notas aproximam-se mais do limite agudo deste mecanismo. Nesta parte aguda, a tensão interna nas cordas vocais é maior e o timbre é consideravelmente diferente da parte grave do mesmo registro, um dos motivos pelos quais esta parte aguda da voz de peito é por vezes assimilada a outro registro, chamado frequentemente "voz de cabeça" (LEOTHAUD, 20042005, p.41-42). A linha do contrato possui em geral mais variações de dinâmica que a primeira e a segunda. Ela faz crescendos em notas de entrada e suas notas de fim de frase são enfraquecidas em direção à pausa. As passagens de maior amplitude são um pouco mais fortes que a intensidade geral da linha da primeira. Assim como sua liberdade em relação à rítmica da melodia principal, 0 contrato tem certa liberdade quanto à execução da letra de uma peça. Além de omitir algumas silabas e palavras, sua dicção é menos clara que a da primeira. Algumas sílabas são categoricamente substituídas por vocalizes.

Os requinteiros utilizam voz de falsete ("Mecanismo II"), num timbre menos rico em harmônicos que a voz de peito. 
Eles fazem um pouco mais de variação de intensidade que a linha do contrato, com crescendos e decrescendos ainda mais acentuados em notas longas de início e fim de cada intervenção. Sem dúvida, a requinta é a parte que menos pronuncia os fonemas das letras. Versos inteiros são "traduzidos" em vocalizes, apenas algumas palavras (isso varia um pouco de cantor para cantor) restam inteligíveis.

Diversos então são os parâmetros que diferenciam cada parte vocal. Elas são produzidas em regiões diferentes do espaço das alturas; elas começam a soar em momentos diferentes, segundo uma ordem previsivel; têm timbres particulares; são cantadas com intensidades diferentes; e com pronúncias especificas das letras. Existe enfim uma grande transparência entre cada parte vocal executada por cada folião: podemos bem distinguilas auditivamente. Aliás, alguns parâmetros chamam a atenção do ouvinte a diferentes partes em momentos diferentes da performance, como à entrada de uma delas, ou em notas fortes de outra. 0 ouvinte pode mesmo por um momento não escutar com clareza alguma das vozes, dependendo da disposição física de seu cantor em relação aos outros, ou da movimentação dos foliões durante uma dança, mas dificilmente ele vai confundir vozes diferentes que soam ao mesmo tempo.
Mas enquanto estas características colaboram na distinção entre as diferentes partes cantadas, elas dificultam consideravelmente, por outro lado, a apreensão da letra veiculada por estas vozes. Os vocalizes do contrato e principalmente da requinta, cantados com grande amplitude e com ataques ligeiramente defasados em relação às linhas da primeira e da segunda, mascaram absolutamente a letra articulada por estas vozes em vários momentos das peças. A disposição física dos cantores e do público apoia ainda frequentemente esta empreitada. Não teremos espaço para tratar da composição coreográfica do paulista e da disposição física de seus quatro cantores, mas ressalto apenas que estes se deslocam em alguns momentos do canto, e que este deslocamento sempre parte e chega a uma configuração onde os foliões que cantam a primeira e a segunda encontram-se paralelos e de frente ao contrato e a requinta, estes também paralelos entre si. Estas duas "duplas" se dispõem aqui como se ocupassem cada uma um lado oposto de um quadrado. Elas cantam basicamente de frente uma para a outra e de lado ou de costas para o público. A cada vez que se movimentam, elas trocam de lado e o público escuta com maior proximidade ora a primeira e a segunda, ora o contrato e a requinta. 0 Ex.3 ilustra um destes momentos de movimentação dos foliões durante um paulista.

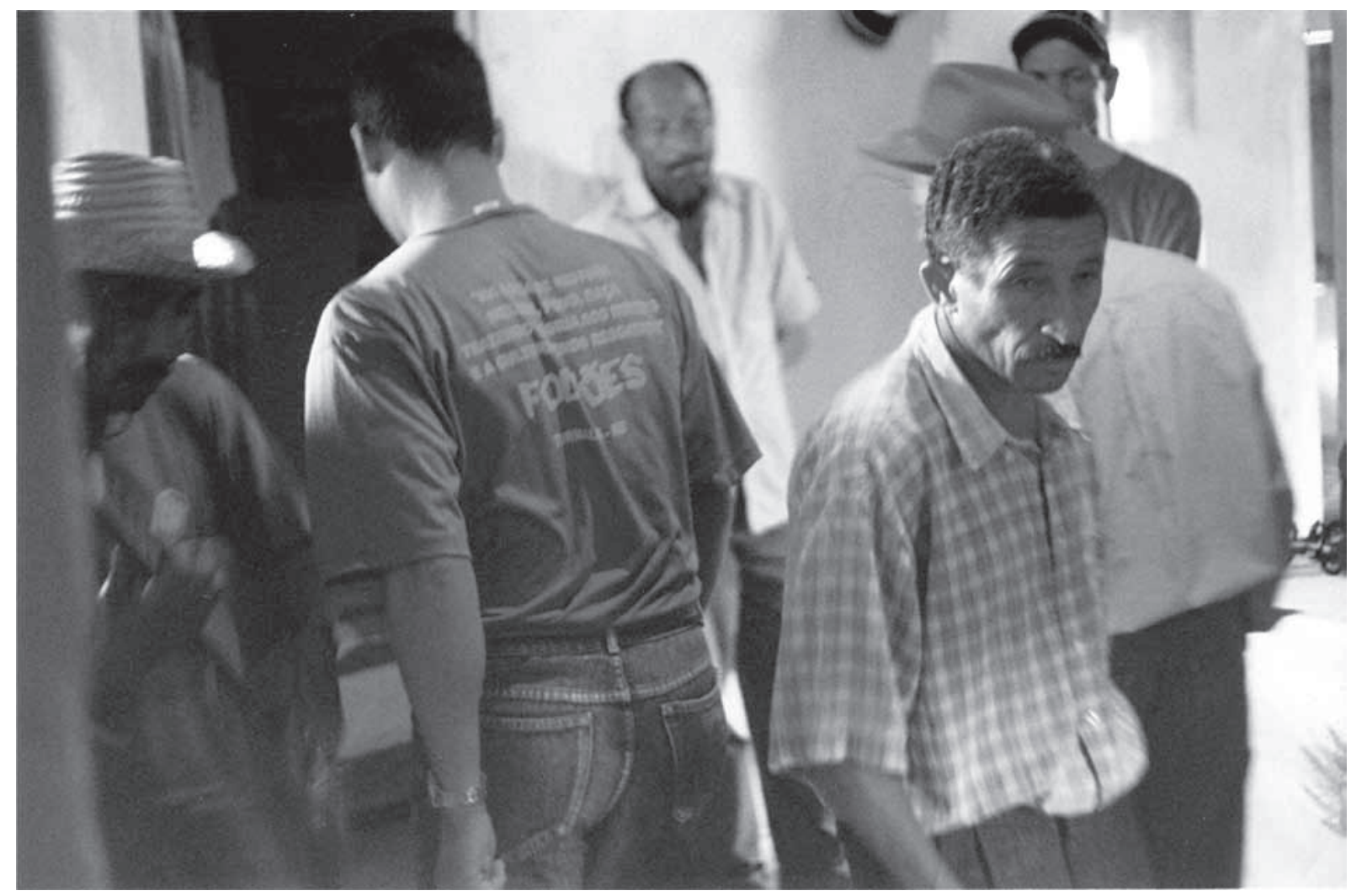

Ex.3 - Quatro foliões brincam um paulista. 0 senhor de camisa xadrez canta a primeira. 0 que toca violão canta a segunda. Eles estão de frente para o fotógrafo. 0 senhor com um chapéu de feltro e o outro que também está de costas cantam respectivamente o contrato e a requinta. 0 público se dispõe aos cantos do cômodo. 


\section{4 - Procedimentos de estruturação formal - o conteúdo velado pela forma}

Também chamado de "quatro", o paulista é executado por quatro foliões que alternam ciclicamente seções musicais cantadas a cappella a uma seção instrumental composta de sapateado, palmas e violão. Como um tipo de interlúdio, esta seção instrumental é sempre retomada da mesma forma, sob o mesmo texto musical, tanto dentro de uma peça, quanto entre diferentes peças. Contudo, ela não é alvo de uma execução rígida, estrita, ou rigorosamente fiel a um texto original, mas aberta a pequenas variações de uma performance a outra, aliás como todo o corpus musical dos foliões de Turmalina.

Esta seção tem uma métrica regular e marcada. Os diferentes trechos cantados de diferentes peças, em oposição, obedecem a um tempo musical não mensurado, a uma rítmica relativamente lenta e rubato, muito sujeita a variações que se aproximam mais ou menos de um andamento regular, e a diferenças muito fluidas ou inexistentes entre tempos fortes e fracos.

$\mathrm{Na}$ maior parte das vezes uma peça de paulista é organizada em quatro seções cantadas, sempre introduzidas, intercaladas e finalizadas pela seção instrumental. Argumentam os foliões que qualquer peça pode ser executada também em duas ou três seções cantadas. Neste caso, a mesma letra que pode ser dividida em quatro seções, é disposta em duas ou três, mas não reduzida. Não se muda tampouco a ordem em que são apresentados os versos desta letra, nem a melodia sobre a qual são cantados, mas apenas o maior ou menor número de interseções instrumentais que os divide. No entanto, ao menos atualmente, vemos apenas raramente realizações de paulistas em três seções cantadas, as execuções em quatro seções sendo de longe as mais frequentes.

Tomemos como exemplo, para nossa análise, uma versão em quatro partes cantadas de um paulista, brincada na manhã de um domingo em junho de 2006, na sala de entrada de uma casa em Turmalina. A letra das quatro seções cantadas nesta peça é reproduzida abaixo, na ordem do canto. Levando em consideração esta ordem, e para facilitar a descrição da peça, proponho chamarmos tais seções de 1, 2, 3 e 4, e a seção instrumental de $X$.

\section{(seção instrumental)}

Você mandou eu cantar

Na mente que eu não sabia

Adeus Maria Cocota

Adeus Cocota Maria

\section{(seção instrumental)}

Mas eu chamo quebra-asa

Da meia-noite pro dia

Adeus Maria Cocota

Adeus Cocota Maria

(seção instrumental)
Embarquei no trem de ferro Às onze e meia do dia

Embarquei no trem de ferro

Às onze e meia do dia

(seção instrumental)

Menininha adeus adeus

Cá eu volto outro dia

Adeus Maria Cocota

Adeus Cocota Maria

(seção instrumental)

Não apenas nesta peça, mas de forma geral em todas as peças de paulista, as seções 1, 2 e 4 possuem o mesmo texto musical. Não se trata de um único trecho melódico comum a peças diferentes (como a seção instrumental), mas de melodias específicas a cada peça, dentro das quais ocupam igualmente as seções 1, 2 e 4. Desta forma, nestas seções o canto é estrófico.

Poderíamos transcrever musicalmente esta peça como no Ex.4, onde os primeiros três sistemas de cada página constituem a seção $X_{i}$ o quarto e quinto sistemas da primeira página constituem as seções 1,2 e 4 ; e o último sistema a seção 3.

As seções estróficas (1, 2 e 4) são terminadas sempre por um bordão, tanto da letra quanto da melodia. Como veremos, este bordão é formado pelos dois últimos versos (versos) do verso (estrofe) que caracteriza esta peça, aquele que the é exclusivo e sempre presente em seu interior. As seções 1 e 2 são iniciadas por um verso (estrofe) jogado, composto de quatro versos (versos): os dois primeiros são cantados ao início da seção 1 e os dois últimos ao início da seção 2, o que faz com que estas duas metades sejam cantadas sobre o mesmo trecho musical. No exemplo acima, cantou-se "Você mandou eu cantar / Na mente que eu não sabia" sobre as duas primeiras frases musicais da seção 1; e "Mas eu chamo quebra-asa / Da meia-noite pro dia" sobre as duas primeiras frases musicais de 2 .

Estes versos jogados não têm, em princípio, nenhuma relação semântica de complementaridade com o bordão. Aliás, esta é uma vocação geral de versos jogados: uma mesma estrofe pode ser utilizada em diferentes peças, ou estrofes diferentes em diferentes execuções de uma mesma peça.

A seção 3 de um paulista é a única das seções cantadas onde o texto musical é diferente, mesmo que por vezes (como neste exemplo) ele seja um resumo das outras seções, composto exclusivamente de excertos do texto musical destas. Aqui são apresentados e repetidos os dois primeiros versos (versos) da estrofe característica da peça.

$\mathrm{Na}$ seção 4 são cantados os últimos quatro versos (versos) dos seis versos (versos) que compõem a estrofe característica da peça, sendo que os dois últimos já haviam sido apresentados desde a seção 1: eles são o bordão. 


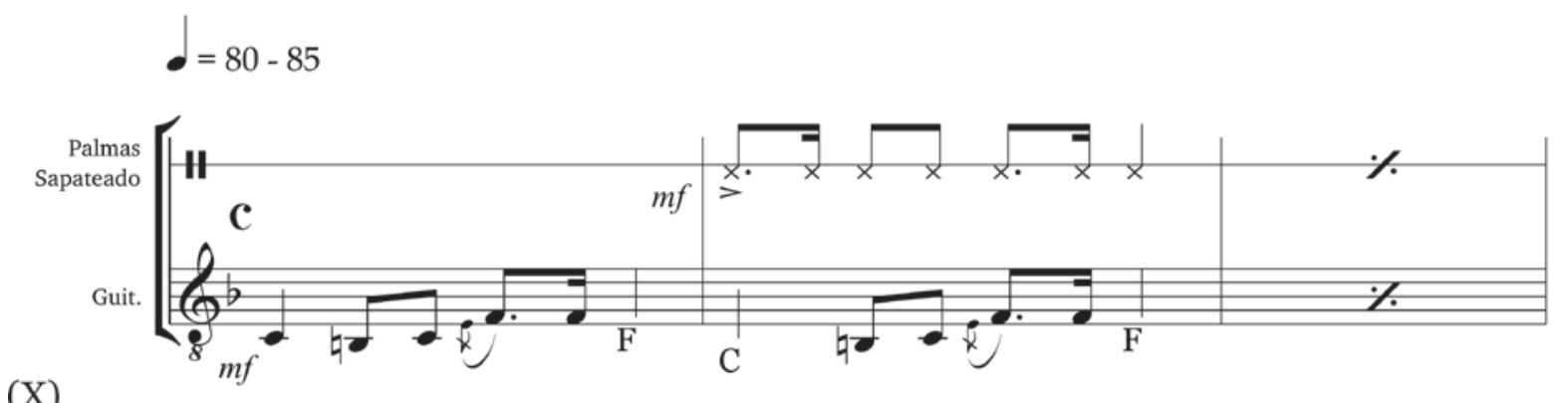

(X)
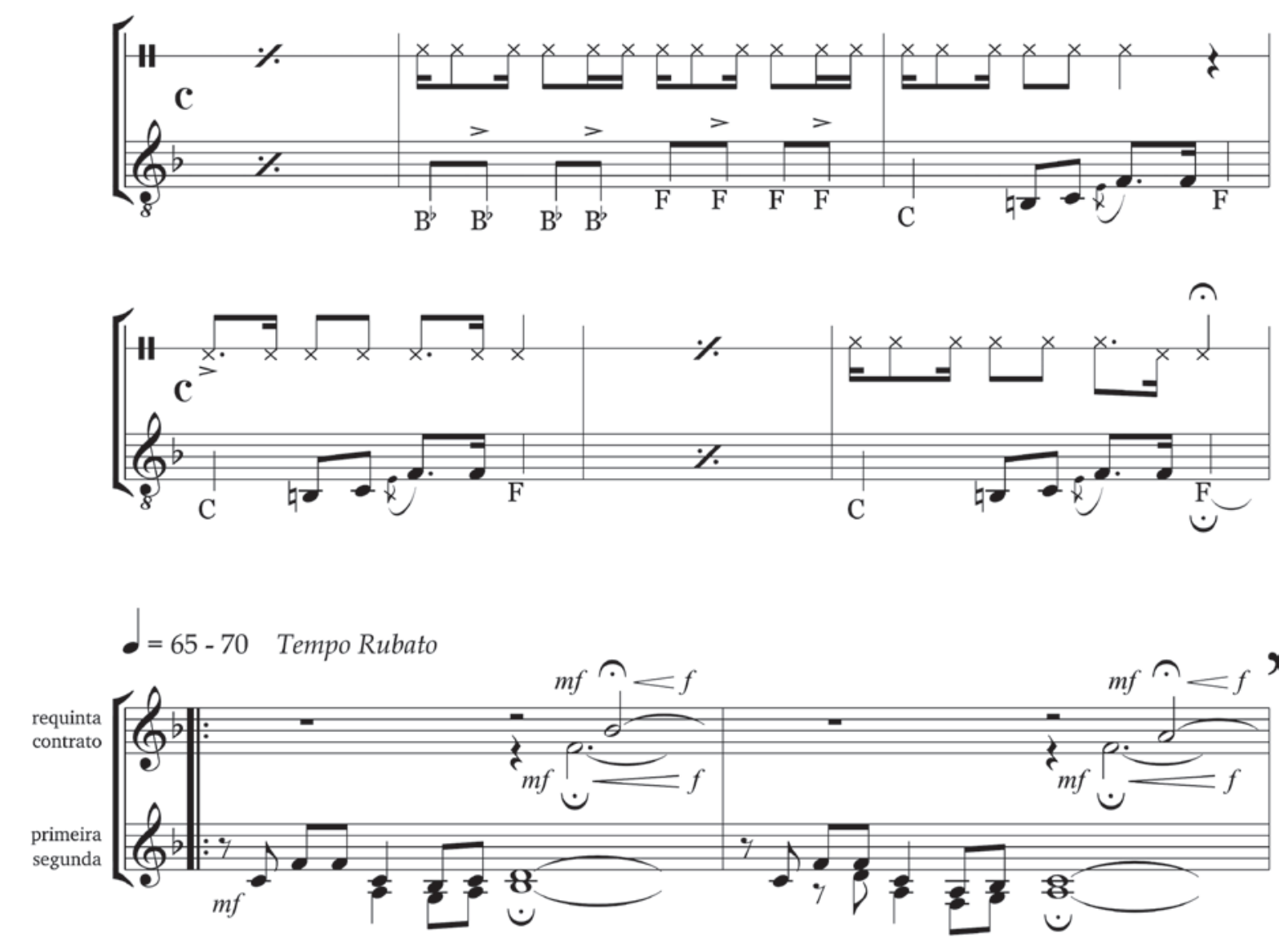

seções (1) Vo - cê man-dou eu can - tar ê ê

(2) Mas eu cha-mo que-bra asa $\hat{\mathrm{e}} \hat{\mathrm{e}}$

(4) Me-ni-ni-nha a-deus a - deus ê ê

Na men-te que eu não sa - bia ê ê

Da mei- a noi - te pro dia ê ê

Cá eu vol-to ou-tro dia ê ê

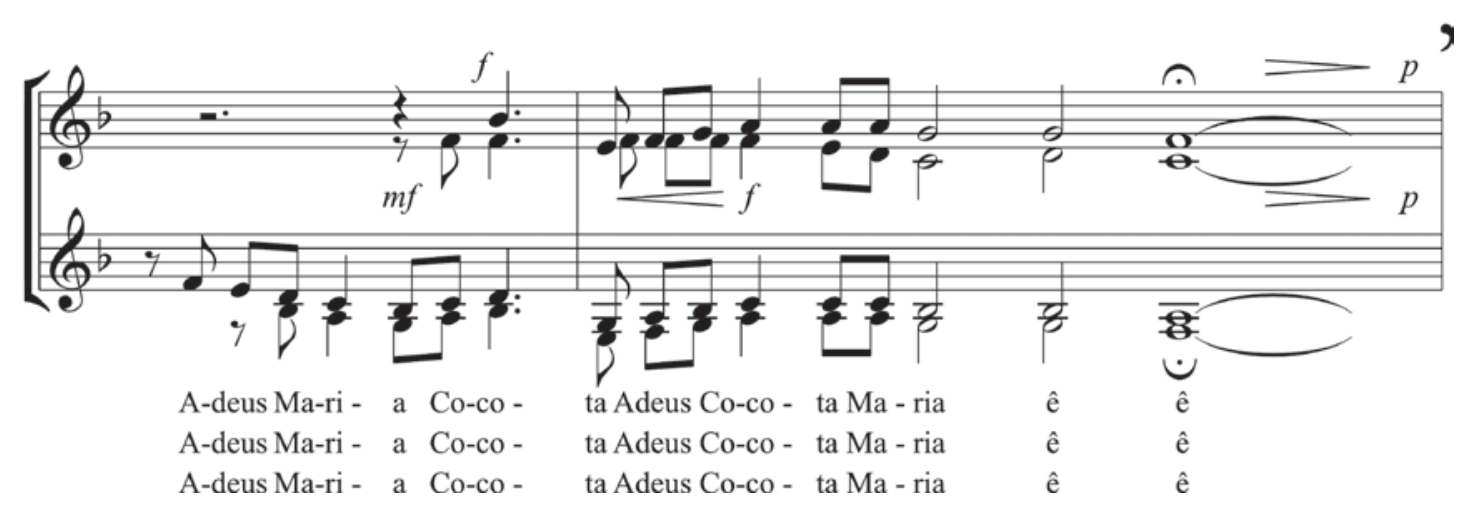

Ex.4 - Transcrição de um paulista. 


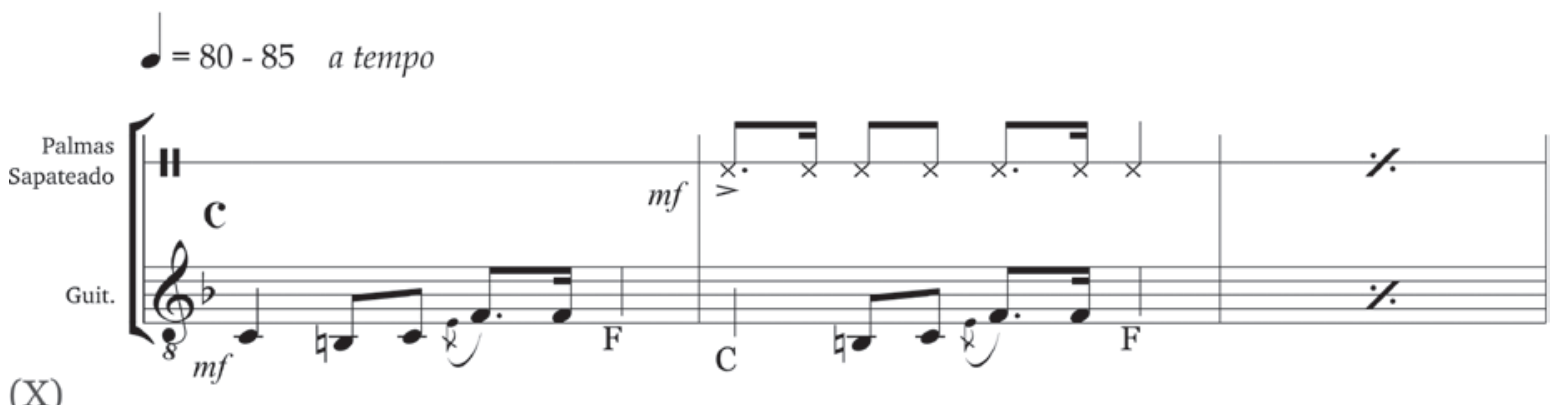

$(\mathrm{X})$
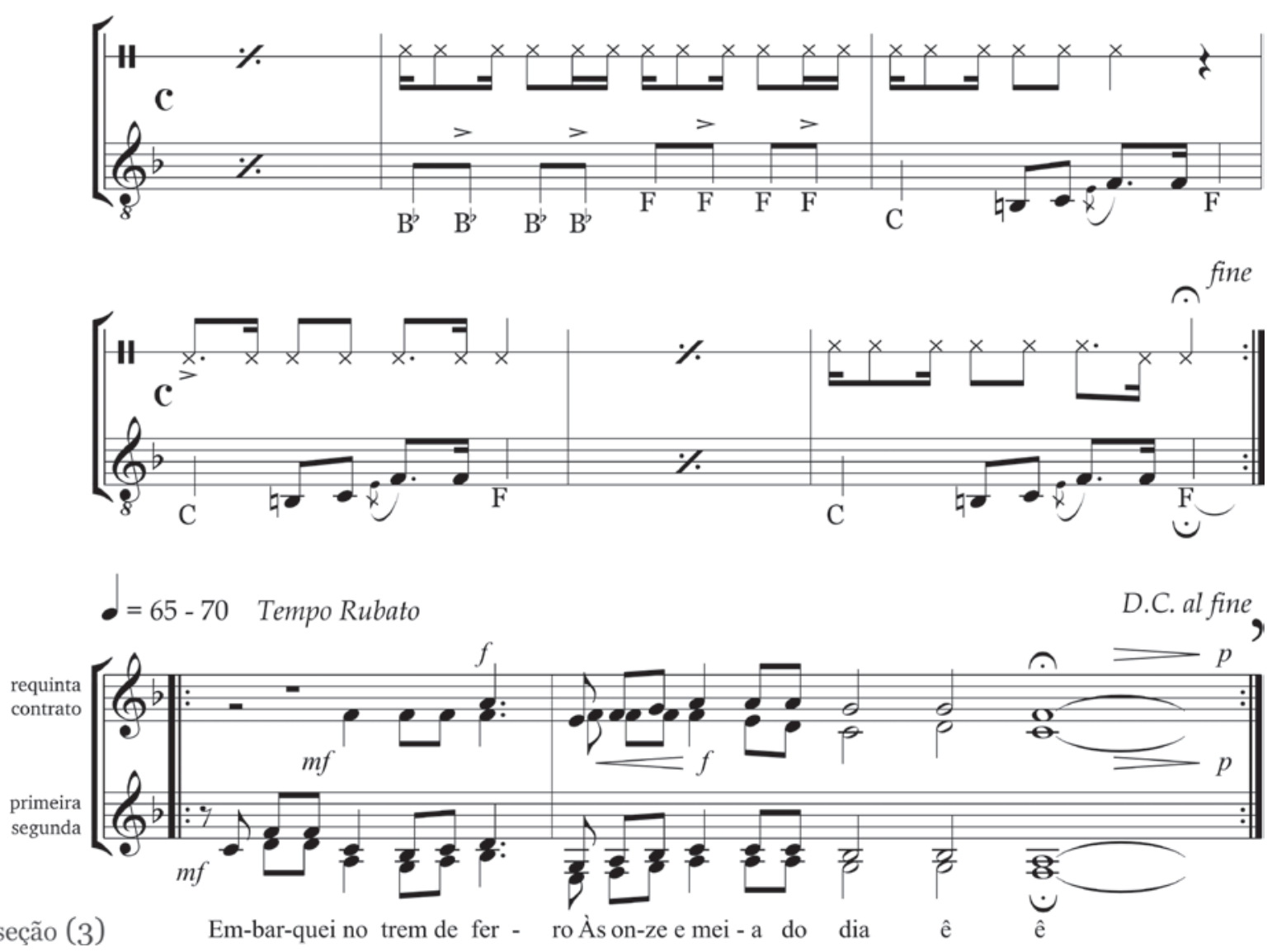

Ex. 4-2

Ou seja, a letra que caracteriza a peça é composta por uma estrofe de seis versos (versos). Os dois últimos destes versos são os primeiros a serem apresentados, dentro da seção 1, e retomados na seção 2 . Na seção 3, o primeiro e segundo versos da estrofe característica são cantados seguidamente duas vezes. 0 terceiro e quarto versos vão ser apresentados na seção 4, seguidos do quinto e sexto versos. Até a seção 4 , não se tem elementos suficientemente claros para se fazer a ligação entre os versos já apresentados (entre o primeiro e o segundo de um lado, e o quinto e o sexto de outro). Só com a exposição do terceiro e quarto versos é que teremos todos os elementos necessários para a correspondência semântica entre todos os versos, para a construção da estrofe completa, em seu sentido pleno. 0 bordão, cujo sentido era obscuro no início da peça, não apenas ganha sentido costurado ao resto do texto, mas fecha a seção 4 como uma conclusão, como um arremate que diz: "agora você entende o que querem dizer estas palavras, repetidas misteriosamente deste o início do canto".

Poderíamos resumir a estrofe característica desta peça como:

Embarquei no trem de ferro

Às onze e meia do dia

Menininha adeus adeus

Cá eu volto outro dia

Adeus Maria Cocota

Adeus Cocota Maria 
Um adeus, melancólico, certamente entre um casal de namorados. 0 rapaz partiu no trem das onze e meia despedindo-se de Maria Cocota e prometendo voltar. Paralela a esta estrofe exclusiva desta peça, apresentase outra, o "verso jogado", cujo sentido só pode ser igualmente deduzido na junção de fragmentos de diferentes seções musicais. Trata-se de uma estrutura literária que embora aconteça no tempo, exige uma leitura não-linear, ou também não-linear, além de fragmentada e polifônica.

Se resumirmos a "melodia característica" desta peça, a melodia principal colada a sua estrofe característica (transcrita abaixo, no Ex.5), veremos que também sua exposição exige uma leitura fragmentada. As frases musicais coladas ao primeiro e segundo versos são respectivamente as mesmas do terceiro e sexto versos. Poderíamos supor que se trata de um só texto musical, apresentado de forma resumida ou fragmentada num momento (primeiro sistema abaixo), e desenvolvida ou integral em outro (segundo e terceiro sistemas). Nota-se também neste caso a analogia estrutural entre as frases musicais coladas ao quarto e quinto versos (versos), no plano melódico, e os versos terceiro e quarto em si, no plano das letras: ambos pares ligam duas extremidades de um conteúdo.

A composição é aqui um jogo que parte de elementos dispersos, reunidos gradativamente numa unidade. Ela propõe um enunciado coerente e inteiro e ao mesmo tempo dificulta sua apreensão, através de várias pequenas táticas formais, através da própria forma de apresentar seus elementos. Trata-se da proposta quase deliberada de um enigma, de um desafio de percepção.

Normalmente, os versos (versos) pares da estrofe característica de um paulista rimam entre si. Na execução apresentada acima, os versos (versos) pares do verso (estrofe) que foi jogado rimam também com os versos (versos) pares da estrofe característica da peça (sabia, dia, dia, dia, Maria). Mas raramente são jogados versos que rimam com o resto do texto. E nos casos mais numerosos, os bordões só vão rimar com o segundo verso da seção 3, entre seções diferentes, e com o segundo verso da seção 4, dentro de uma mesma seção. Estas rimas nos assinalariam então os versos da estrofe característica, elas marcariam uma unidade entre estes e uma diferença em relação ao verso jogado. Mas além da grande distância guardada entre estas rimas, os foliões preenchem ainda notas longas de fim de frase com pequenas palavras cantadas, palavras sem conteúdo semântico tais como: "aiai", "lelê", "ei", "ê", "lalá". Estas palavras marcam então o fim de quase todos os versos (versos) das peças, dissolvendo ou sabotando eventuais rimas entre estes.

Em todas as peças de paulista que escutei, uma mesma frase musical é colada ao segundo e ao último verso da estrofe característica. Ou seja, na ordem em que são cantadas, a última frase musical de cada seção cantada. É um bordão musical colado à metade do bordão da letra nas seções 1, 2 e 4 e independente deste na seção 3. Ela afirma o bordão da letra em 1, 2 e 4 e trai o ouvido em 3 , insinuando o status de bordão ao que na verdade é o segundo verso (verso) da estrofe característica.
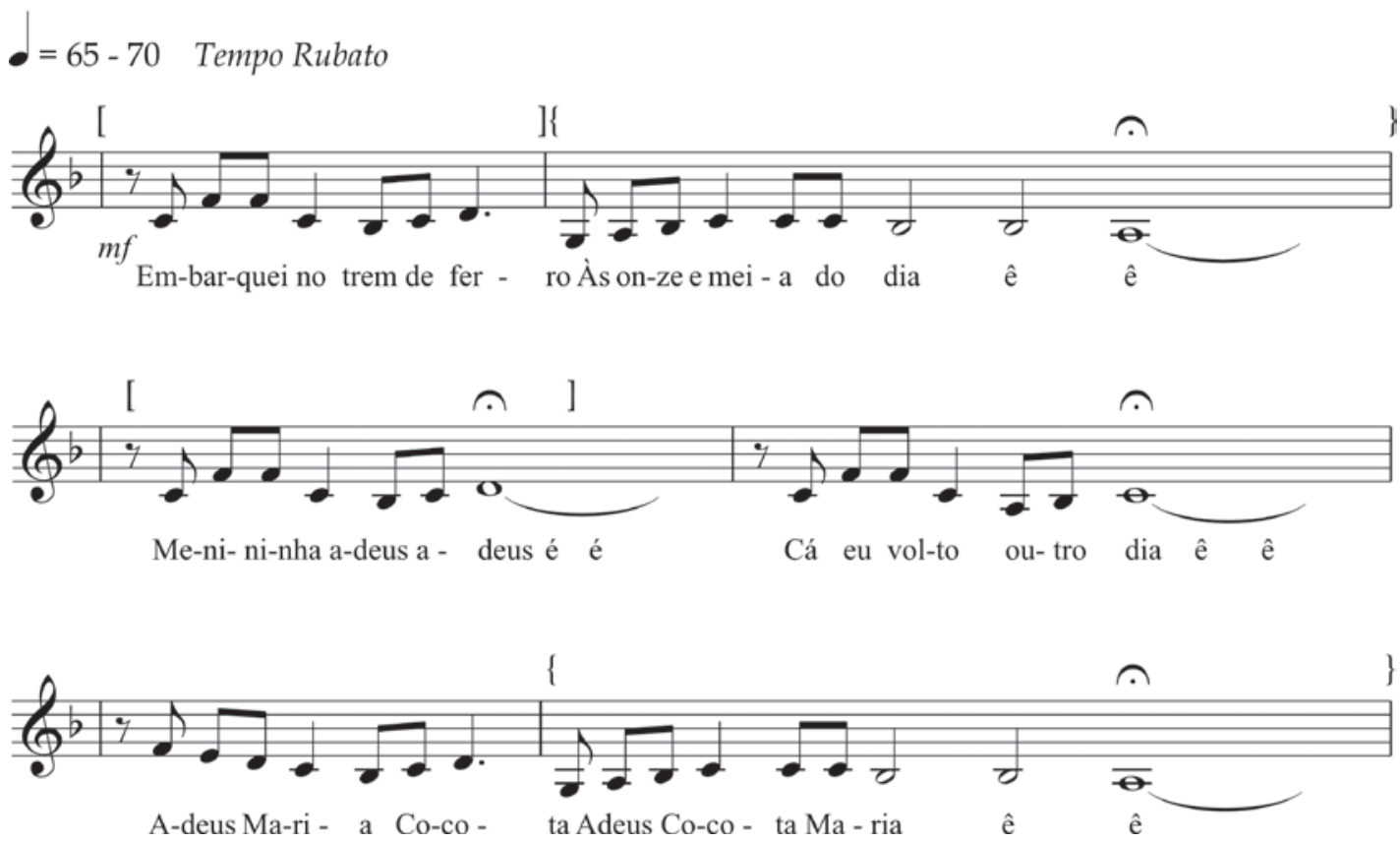

Ex.5 - "Melodia característica" do paulista analisado: a melodia principal colada a sua estrofe característica. 
A primeira e segunda frases musicais de 1, 2 e 4 nos traem da mesma forma. Em 1 e 2 estas frases musicais são relacionadas a versos jogados; em 4 elas nos surpreendem, coladas a versos da estrofe característica. Acentua esta confusão a discrição reservada à apresentação destes versos. Trata-se do terceiro e quarto versos da estrofe característica, cuja importância para a completude da estrofe já foi evocada. No entanto, é o único par de versos da estrofe característica cantado uma só vez a cada execução, assim como os dois pares do verso jogado. Os dois primeiros versos da estrofe característica são cantados duas vezes na seção 3 . Os dois últimos são cantados três vezes, ao fim de 1, 2 e 4.

\section{5 - Discurso e análise musicológicos}

Diversos são então os procedimentos técnicos que restringem a apreensão do conteúdo semântico da letra. A total compreensão do canto estaria aqui reservada a um número restrito de ouvintes, e mesmo de cantores. É frequente, por exemplo, que um folião seja capaz de cantar uma peça seguindo outros colegas mais experientes, sem ter entretanto uma consciência muito precisa do conteúdo do que está sendo cantado. Aliás, outros autores já observaram situações semelhantes em contextos musicais não muito distantes. KIMO, por exemplo, o ressalta em um grupo de foliões em Montes Claros (Minas Gerais). Ao perguntar ao Mestre Joaquim Poló, o principal folião deste grupo, se um outro membro do "terno" conhecia um determinado verso cantado frequentemente, o autor obteve a seguinte resposta:

\footnotetext{
"Não. Só compade Sula. Ele segue Sula. Compade Sula fala pra ele o verso. Mas na hora que o verso entrou, que ele falou, aquele verso que entrou na cabeça, que ele acabô de falar, aquele verso, você pode perguntá pra ele que ele não sabe o quê que é. Dinzão (Dim) canta comigo. Depois de terminar de cantar o verso, você pergunta ele o quê que é, que ele não sabe. Vai passar saber daqui a uns tempos né". (2006, p.41)."
}

Mas além dos mecanismos formais que contribuem à restrição da apreensão musical, uma grande economia no que concerne qualquer forma de discurso não-musical sobre a música apoia também de forma importante este regime de escuta. 0 sistema musical dos foliões parece reservar seu espaço central à prática musical em si, à ação musical, em detrimento de qualquer tipo de representação. Toda a instrução musical de um folião, por exemplo, passa pela observação e imitação, processos que priorizam a experiência musical em sua forma mais concreta, em despeito de abstrações ou de sistemas de teorização. É bastante reduzido, inclusive, o vocabulário musicológico descritivo ou analítico dos foliões. Além da classificação dos gêneros musicais, das partes vocais e de algumas noções como "jogar verso", poucos termos são empregados para se referir a aspectos, parâmetros ou processos de composição musical ou poética. Assim como a palavra "verso", há alguns termos de significado polissêmico ou impreciso, empregados com acepções diferentes e imprecisas segundo seus contextos de utilização. Não há tampouco qualquer discurso que teorize a sistematização da condução melódica das diferentes partes vocais, nem discurso sobre a organização harmônica destas. Mesmo se considerarmos a prática musical em si, veremos que ela se baseia no exercício musical integral. Isto é, não se costumam isolar parâmetros ou partes, mesmo para um ensaio ou um processo de treinamento. Tampouco são utilizadas representações visuais ou táteis para o aprendizado técnico, como no aprendizado de instrumentos musicais não apenas em sistemas musicais baseados na escrita, mas também em diversos sistemas musicais de tradição oral, onde movimentos de dedos, posições e gestos corporais e instrumentais são descritos e relacionados a sons musicais. Enfim, não há aqui um sistema expressivo de metáforas para sons musicais ou para sua organização, embora como temos visto, tratese de uma música bastante sistematizada, e de uma sistematização bastante estrita.

\section{6 - Cantiga de roça e considerações finais}

Proponho agora um breve desvio por um outro gênero musical relacionado aos foliões, para em seguida voltar ao paulista e concluir nosso texto. Trata-se da "cantiga de roça", também chamada "canto de capina", "mutirão" ou ainda "reúna", uma música muito importante na região até o início dos anos 1970, mas atualmente em desuso. Este gênero exclusivamente vocal embalava mutirões de trabalho na roça. "Mutirão" era um sistema de trabalho coletivo e de troca de mão-de-obra baseado em relações de reciprocidade e comunitarismo muito corrente no médio Jequitinhonha, até aproximadamente os anos 1970. Sitiantes vizinhos aliavam-se para campanhas de trabalho agrícola que exigiam mão-de-obra numerosa, reunindo-se consecutivamente na roça de cada um dos envolvidos, até que todos tivessem sua solicitação satisfeita e proporcionalmente retribuída. Sempre que havia alguns foliões entre os companheiros que trabalhavam, e a narrativa do grupo de Turmalina relata que sempre os havia, as cantigas de roça eram entoadas durante o trabalho, revezadas entre conjuntos de quatro trabalhadores/cantores durante toda a jornada.

Dentro das campanhas de mutirão, ao fim de cada dia de trabalho, o anfitrião do dia oferecia uma festa em sua residência, onde se reuniam os trabalhadores e também suas famílias nucleares. Além de um sistema de cooperação vicinal, o mutirão representava sistematicamente um tipo de festival comunitário, um período que podia se estender por mais de uma semana, onde os dias eram marcados pelo trabalho coletivo dos homens e pelas cantigas de roça, e as noites preenchidas de festas, com outros gêneros musicais ${ }^{4}$.

Durante minhas estadias em Turmalina, tive a oportunidade de escutar alguns poucos cantos de capina, apresentados fora de contexto por alguns foliões, apenas como uma forma de me explicarem como aconteciam estes cantos durante o trabalho na roça, algumas décadas atrás. Esta audição superficial sempre me causou a impressão de grande semelhança estilística entre este gênero e o paulista. De fato, em várias outras ocasiões 
alguns foliões me explicaram que estes dois gêneros são muito próximos. Com exceção das seções instrumentais e de movimentos coreográficos, inexistentes no canto de capina, a estruturação formal deste e do paulista é a mesma. Há inclusive peças de canto de capina correntemente cantadas como paulistas, bem como havia o inverso, quando as primeiras eram ainda praticadas. A adaptação nestes casos é muito simples, bastando acrescentar ou suprimir a dança e as seções instrumentais das peças. Há ainda peças indicadas duplamente como paulistas e cantos de capina.

BRANDÃO (1983, p.82-91) descreveu um mutirão no município de São Luís do Paraitinga (São Paulo), cuja dinâmica parece muito semelhante aos mutirões de Turmalina: o dia marcado pelo trabalho coletivo na roça, embalado por cantos de trabalho, chamados de "brão" em São Luís do Paraitinga; e a noite por uma festa na casa do anfitrião, o "patrão" do dia. Nestes brãos, duplas de trabalhadores/cantores se revezavam no canto de versos de saudação e de versos enigmáticos (chamados "linhas"), charadas cujas resoluções eram buscadas pelos outros companheiros de trabalho durante toda a jornada. Ao longo do dia, as duplas ofereciam ou solicitavam através do canto, a cada alternância, novos elementos para a solução dos enigmas, acumulando pouco a pouco condições cada vez maiores para as resoluções dos problemas. Companheiros que conseguissem decifrá-los apresentavam a resposta também através do canto. Ao fim do dia de trabalho, caso ninguém tivesse conseguido resolver o enigma proposto por uma dupla, os próprios cantores o revelariam fora de contexto musical, como um dos assuntos das conversas entre os companheiros. Um certo prestígio parecia ser alcançado seja por quem foi capaz de resolver um enigma, seja pelos cantores que conseguiram sustentá-lo insolúvel até o fim do dia. 0 principal interesse deste exercício parece ser 0 desafio, o jogo de dedução, de solução de uma charada, independente das informações nela contidas.

No canto de capina ou no paulista de Turmalina, as letras não giram em torno de uma charada, ou de um problema deliberadamente proposto, tampouco original (todos podem conhecer de antemão as peças que são cantadas). No entanto, um certo enigma é proposto, como sugeri acima, na apresentação de versos parcialmente velados pela forma de cantar, fragmentados e embaralhados, acumulados durante o canto até formarem um sentido de conjunto, completado ao fim da peça. Mas se este "sentido" pode ser deduzido a partir de elementos apresentados dentro da própria peça, esta trabalha também em sentido contrário, em camuflar esta coerência, restrita então a um número reduzido de companheiros, experientes 0 suficiente para conseguirem deduzi-la. Aliás, muitos são não apenas os ouvintes e foliões que não enxergam a resolução deste "enigma", mas os que não enxergam nem mesmo sua existência. Talvez a própria proposta deste enigma se faça através de um enigma.

0 conteúdo semântico das letras é, no paulista como em outros gêneros dos foliões, um elemento de importância central da composição. Ele não representa apenas um enunciado poético, livre e impessoal: as letras se inserem constantemente em trocas de gentileza, de brincadeiras e de reconhecimentos entre cantores e público, se conectando a diversos eventos extra-musicais das ocasiões ${ }^{5}$. Mas, além deste papel dialógico mais direto, as letras cantadas pelos foliões parecem desempenhar um outro tipo importante de comunicação, que depende apenas indiretamente de um conteúdo semântico específico. Todas as nuanças presentes na composição de um paulista nos mostram que, qualquer que seja 0 significado de um conteúdo semântico (e paralelamente a ele), compreendê-lo, já é em si um fim comunicacional. 


\section{Referências}

BRANDÃO, Carlos R. Os Caipiras de São Paulo. São Paulo: Brasiliense, 1983.

CANDIDO, Antonio. Os parceiros do Rio Bonito: Estudo sobre o caipira paulista e a transformação dos seus meios de vida. São Paulo: Livraria Duas Cidades e Editora 34, 2003 [1964].

CASTELLENGO, Michèle. Les deux principaux mécanismes de production de la voix humaine, leur étendue et leur utilisation musicale. Ext. du colloque La voix dans tous ses éclats. Paris: Centre Pompidou, 1986.

CASTELLENGO, Michèle. Continuité, rupture, ornementation, ou les bons usages de la transition entre deux modes d'émission vocale. La voix et les techniques vocales - Cahiers de musiques traditionnelles 4, p.155-165. Genève: Ateliers d'ethnomusicologie, 1991.

CASTELLENGO, M.; ROUBEAU, B. Revision of the notion of voice register. XIX॰ International CoMeT Congress. Utrecht, 1993.

CASTELLENGO, M.; ROUBEAU, B. Voice Range Profile in relationship to laryngeal vibratory mechanisms. International CoMeT Congress. Paris, 1997.

KIMO, Igor J. Música, Ritual e Devoção no Terno de Folia de Reis do Mestre Joaquim Poló. Belo Horizonte: UFMG, 2006. Dissertação de Mestrado em Música.

LÉOTHAUD, Gilles. Théorie de la Phonation. Paris: Université Paris Sorbonne - Paris IV, 2004-2005. Cours de DEUG 2ème année. Disponivel em: <http://www.paris4.sorbonne.fr/e-cursus/texte/CEC/Gleothaud/leothaud.htm>. Acesso em: 26 mar. 2009

MARCHI, L.; SAENGER, J.; CORRÊA, R. Tocadores - homem, terra, música e cordas. Curitiba: Olaria, 2002.

MOREIRA, Roberto J. Ruralidades e globalizações: ensaiando uma interpretação. In: R. J. Moreira (org.), Identidades Sociais - Ruralidades no Brasil contemporâneo. Rio de Janeiro: DP\&AA, 2005, p.15-40.

RODRIGUES, Davidson de 0. Jeca Tatu e os dilemas da modernização rural no Brasil. In: E. L. Borges (org.), Campo e Cidade na Modernidade Brasileira. Belo Horizonte: ARGUMENTUM, 2008, p.13-40.

ROSSE, Leonardo P. Folia, Musique et Sociabilité à Turmalina (Brésil). Saint-Denis: Université Paris 8, 2009a. Dissertação de Master I/ em Etnomusicologia.

Eu agora estou ciente que meus companheiros é bom - Folia, Música e Sociabilidade em Turmalina. Brasilia: Domínio Público, 2009b. Tradução e adaptação da dissertação Folia, Musique et Sociabilité à Turmalina (Brésil). Disponivel em: <http://www.dominiopublico.gov.br/pesquisa/DetalheObraForm.do?select_action=Etco_ obra=165983>. Acesso em: 01 set. 2010.

\section{Notas}

1 Este artigo é uma reelaboração de ideias ensaiadas inicialmente em minha dissertação de Master II (ver Rosse 2009a). Tento retomar aqui parte da descrição original, desdobrando-a em uma análise e problematização mais estritas e aprofundadas.

2 Propus em outros trabalhos uma análise sociológica de diferentes agentes ligados à prática musical dos foliões de Turmalina (ROSSE, 2009a e 2009 b). Neste quadro, foram observadas diferentes formas em que a música articula termos de uma relação interpessoal.

3 Ver por exemplo CASTELLENGO (1986 e 1991); e Castellengo \&t Roubeau (1993 e 1997).

4 Sistemas de mutirão camponês muito semelhantes são descritos por alguns autores em diferentes estados do Brasil. Ver por exemplo: BATISTA (in MARCHI et al. 2002, p.265-268); BRANDÃO (1983, p.78-91); CANDIDO (2003 [1964], p.87-94); COSTA (in MARCHI et al. 2002, p.277-279); PEREIRA, P. (in MARCHI et al. 2002, p.288-289); PEREIRA, J. (in MARCHI et al. 2002, p.297); PEREIRA, A. (in MARCHI et al. 2002, p.300-301).

5 Este papel dialógico das letras cantadas pelos foliões em Turmalina foi razoavelmente demonstrado em outros trabalhos (ROSSE, 2009a e 2009b).

Leonardo Pires Rosse é Bacharel em Composição pela Universidade Federal de Minas Gerais (2003) e Mestre em Etnomusicologia pela Universidade Paris 8, Vincennes - Saint-Denis (França) (2009), onde defendeu a dissertação intitulada Folia, Musique et Sociabilité à Turmalina (Brésil) [Folia, Música e Sociabilidade em Turmalina (Brasil)], sob a orientação de Rosalia Martinez. 